\title{
Changes in Helicobacter pylori Immunoglobulin G Levels and Gastric Mucosal Atrophy after Successful Eradication of Helicobacter pylori
}

\author{
Ji Hye Kim ${ }^{1, *}$, Joon Seop Lee ${ }^{1, *}$, Yong Hwan Kwon ${ }^{1,2}$, Seong Woo Jeon ${ }^{1,2}$, Su Youn Nam ${ }^{1}$, Sun Jin ${ }^{1}$ \\ Department of Internal Medicine, Kyungpook National University Hospital ${ }^{1}$, Department of Internal Medicine, School of Medicine, Kyungpook \\ National University ${ }^{2}$, Daegu, Korea
}

대한상부위장관·헬리코박터학회지에 게재된 위 논문에서 Fig. 1에 오류가 있어 정정합니다.

This correction is being published to correct the Fig. 1 in above article.

Before correction

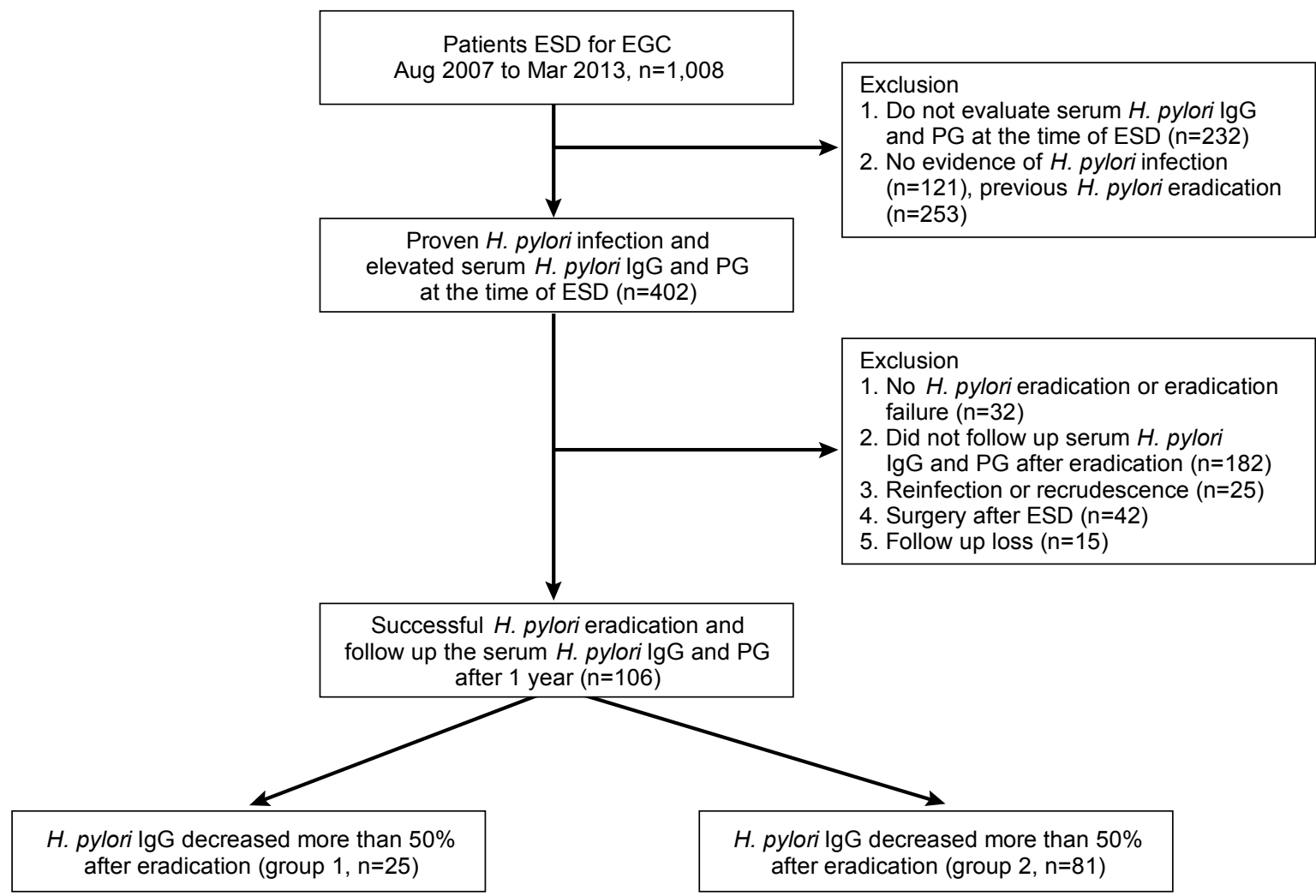

Fig. 1. Schematic flow of this study. ESD, endoscopic submucosal dissection; EGC, early gastric cancer; H. pylori, Helicobacter pylori; IgG, immunoglobulin G; PG, pepsinogen.

Corresponding author: Yong Hwan Kwon

Department of Internal Medicine, Kyungpook National University Hospital, 130 Dongdeok-ro, Jung-gu, Daegu 41944, Korea

Tel: +82-53-200-2609, Fax: +82-53-200-3089, E-mail: tear9754006@yahoo.co.kr

*These authors contributed equally to this work.

Copyright $\odot 2019$ Korean College of Helicobacter and Upper Gastrointestinal Research

(a) The Korean Journal of Helicobacter and Upper Gastrointestinal Research is an Open-Access Journal. All articles are distributed under the terms of the Creative Commons Attribution Non-Commercial License (http:// creativecommons.org/licenses/by-nc/4.0) which permits unrestricted non-commercial use, distribution, and reproduction in any medium, provided the original work is properly cited. 


\section{After correction}

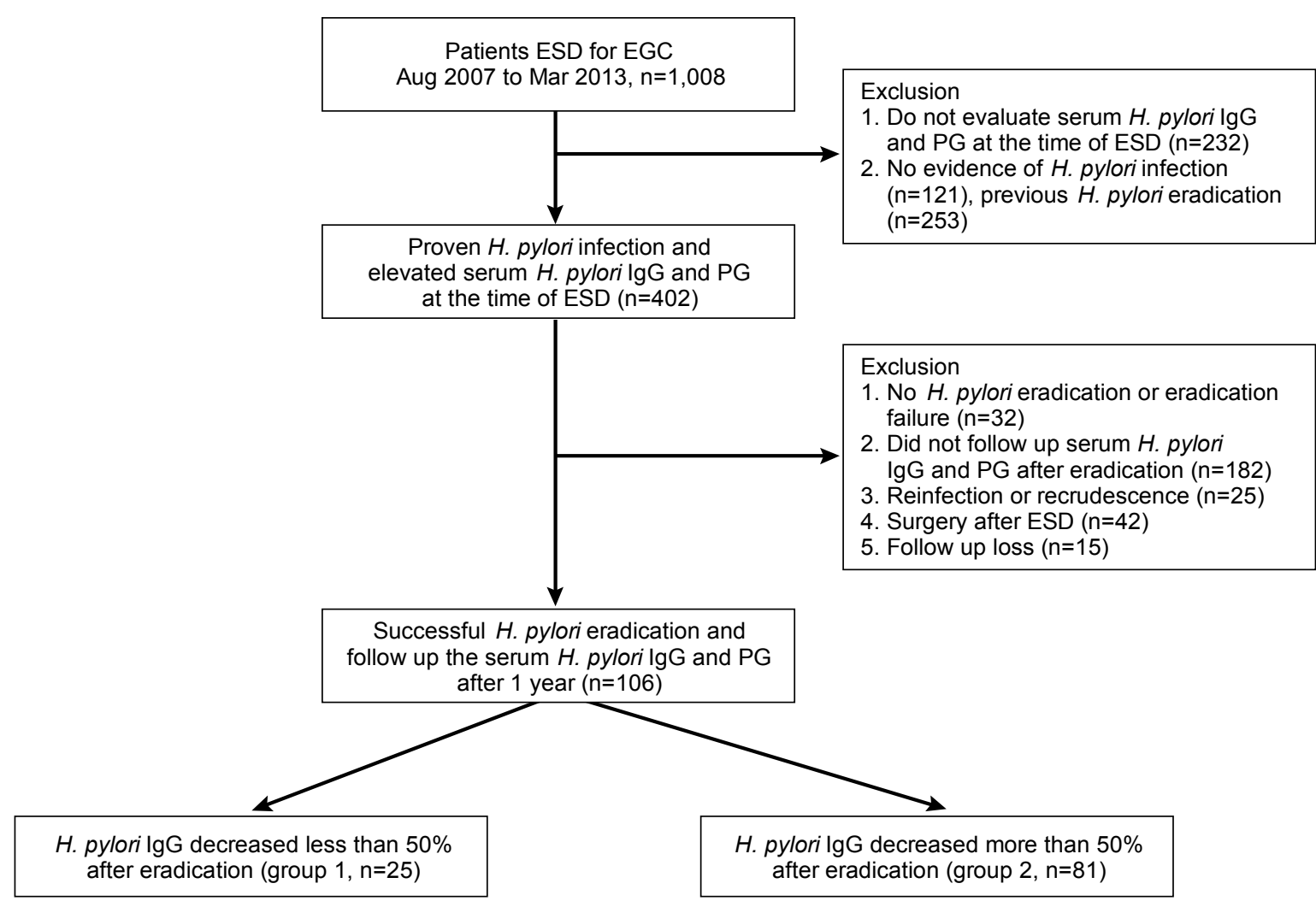

Fig. 1. Schematic flow of this study. ESD, endoscopic submucosal dissection; EGC, early gastric cancer; H. pylori, Helicobacter pylori; IgG, immunoglobulin G; PG, pepsinogen. 